Check for updates

Cite this: RSC Adv., 2017, 7, 29854

Received 7th May 2017

Accepted 29th May 2017

DOI: 10.1039/c7ra05157c

rsc.li/rsc-advances

\section{A fluorescent photochromic diarylethene based on naphthalic anhydride with strong solvatochromism $\uparrow$}

\author{
Shangjun Chen, (D) *a Xin $\mathrm{Li}^{\mathrm{b}}$ and Liwen Song ${ }^{\mathrm{c}}$ \\ A novel "push-pull" diarylethene molecule consisting of an electron withdrawing ethene bridge $(1,8$ - \\ naphthalic anhydride) and two moderate electron donating side chains (2,5-dimethylthiophene) has been \\ designed and synthesized. The photochromism study, together with density functional theory \\ calculations, revealed that the molecule exhibits reversible fluorescence switching capacity upon photo- \\ isomerization and remarkable solvatochromism with red shift of the fluorescence maximum by more \\ than $150 \mathrm{~nm}$ owing to intramolecular charge transfer.
}

\section{Introduction}

Research on bistable diarylethenes has received much attention on account of their photo-isomerization states with distinct absorption spectra, promising fatigue resistance, and excellent thermal stability. ${ }^{1-6}$ In particular, diarylethene compounds exhibiting fluorescence modulation properties, in which the fluorescence could be switched on and off reversibly via the photochromic isomerization between the open- and closed-ring isomers, are desirable for their potential applications in logic gates, information storage and biological sensing by taking the advantages of fluorescence such as sensitivity, convenience, and relative cheapness. ${ }^{7-13}$

Rational molecular structure designs, whether on the side chains or the ethene bridge of the diarylethenes, aiming at regulating the fluorescence have been well reported. ${ }^{\mathbf{1 4 - 2 2}}$ One of the efficient approaches is to replace the traditional ethene bridges (usually perfluorocyclopentene or cyclopentene) with new aromatic fluorophore building blocks. ${ }^{23-26}$ Owing to the diversity of the fluorophores as well as the remarkable structure changes of the aromatic fluorophore groups during photochromic processes, the fluorescence of the diarylethenes can be regulated efficiently and versatility. For example, an interesting fluorescence turn-on photochromic system in which the closed ring-isomer shows unusual intense fluorescence has been reported, with help of a modulated thiophene ring as ethene

${ }^{a}$ Key Laboratory of Resource Chemistry of Ministry of Education, Shanghai Key Laboratory of Rare Earth Functional Materials, Department of Chemistry, Shanghai Normal University, Shanghai, 200234, P. R. China.E-mail: jshchen@shnu.edu.cn

${ }^{b}$ Division of Theoretical Chemistry and Biology, School of Biotechnology, KTH Royal Institute of Technology, SE-10691 Stockholm, Sweden

'Shanghai Key Laboratory of Functional Materials Chemistry, East China University of Science and Technology, Shanghai 200237, P. R. China

$\dagger$ Electronic supplementary information (ESI) available: Synthetic routes, and NMR and high resolution mass spectra of BTE-O. See DOI: 10.1039/c7ra05157c bridge. ${ }^{27,28}$ Employing coumarin chromophore as the central ethene bridge, Yokoyama's group have achieved an amazing photochromic fluorescence photoswitching controlled by both photochromic reactions and $\mathrm{pH} .{ }^{29}$ Recently, our group has also advanced multiple responsive photochromic fluorescence systems, which can be trigged by stimuli such as solvent, ions, electrochemical oxidation and reduction, by introducing sixmembered ring based ethene bridges such as naphthalimide or benzothiadiazoles into molecular framework of diarylethenes. ${ }^{30-32}$

Solvatochromism, which usually describes the distinct change of the absorption and emission spectra that accompanies a change in solvent polarity, is commonly used in chemical and biological research areas to monitor microenvironmental polarity or to study the conformation of proteins. ${ }^{33,34}$ A compound exhibiting evident solvatochromism typically possesses an electron donor and an acceptor, which makes the intramolecular charge-transfer (ICT) extremely sensitive to even small changes in local microenvironment that originates from the variation of solvent polarity. Recently, by introducing different electron-accepting moieties onto the molecule skeleton of tetraphenylethene, Tang et al. developed a series of aggregation-induced emission molecules with remarkable solvatochromism for the construction of light-emitting diodes or fluorescent visualizers for intracellular imaging. ${ }^{35,36}$ More recently, in order to fluorescently distinguish two types of amyloids in tissue, an aminonaphthalene 2-cyanoacrylate (ANCA) derivative with $20 \mathrm{~nm}$ maximal emission wavelength shift when bound to amyloid deposits has been reported. ${ }^{37}$ However, diarylethene molecules with strong solvatochromism and photoswitching properties are relatively rare.

Naphthalic anhydrides are one kinds of widely used fluorescent chromophores with high fluorescence efficiency and chemical stability. Moreover, it is expected that connection of electron donating groups at the C-4 or C-5 positions of the 
naphthalic ring would generate a "push-pull" molecule with an ICT excited state and considerable dipole character. ${ }^{38,39}$ Aim at constructing new diarylethene molecule with novel photoswitchable fluorescence properties and distinguished solvatochromism, a new diarylethene compound, BTE-O, was designed by directly incorporating a fluorescent moiety of 1,8naphthalic anhydrides as a six-membered aryl unit for the center ethene bridge and further introducing two moderate electron donating units 2,5-dimethylthiophene as the side chains. The easily obtained new compound displayed reversible fluorescence switching capacity upon photo-isomerization and exhibits strong ICT character between the naphthalic anhydride based ethene bridge and two substituted thiophene groups, leading to strong solvatochromism with a red shift of the fluorescence maximum greater than $150 \mathrm{~nm}$.

\section{Experimental}

\section{Materials and methods}

NMR spectra were recorded on a Bruker AM-400 spectrometer using tetramethylsilane (TMS) as the internal reference. $\mathrm{CDCl}_{3}$ was used as the solvent. HRMS spectra were measured on a Waters LCT Premier XE spectrometer using methanol or acetonitrile as solvents. UV-vis absorption spectra and fluorescence spectra were recorded on a Varian Cary 100 spectrophotometer and a Varian Cary Eclipse fluorescence spectrophotometer, respectively. Fluorescence quantum yields of BTE-O in different solvents were determined relative to standard quinine sulphate $\left(\Phi_{\mathrm{f}}=0.55\right)$ within an error of $\pm 5 \%$. Fluorescence lifetimes were obtained on an Edinburgh Lifespec-Ps spectrofluorometer (FL920). The photochromic reaction was conducted in situ by continuous irradiation using an $\mathrm{Hg} / \mathrm{Xe}$ lamp (Hamamatsu, LC8 Lightningcure, $200 \mathrm{~W}$ ) equipped with a narrow-band interference filter (Shenyang HB optical Technology) for $\lambda_{\text {irr }}=365 \mathrm{~nm}$ and a broad-band interference filter (Shenyang HB optical Technology) for $\lambda_{\text {irr }}>$ $500 \mathrm{~nm}$. Absorption changes were monitored using a CCD camera mounted on a Princeton spectrometer instrument. The photochromic reaction quantum yields were evaluated by the standard procedures using 3,3'-(perfluorocyclopent-1-ene-1,2diyl) bis(2-methylbenzo[b]thiophene (BTF6) as the reference for photocyclization. The rates of isomerization in the initial stage of the reaction ( $0-5 \%)$ were compared to a reference whose $\Phi_{\mathrm{o}-\mathrm{c}}(35 \%)$ in hexane was known, which resulted in $5 \%$ uncertainties in the calculations of the quantum yields. ${ }^{40}$

\section{Synthesis}

All the chemicals were of analytical grade and commercially available unless otherwise stated and used as received without further purification. All organic solvents were purified by standard methods prior to use. The intermediate BTE-N (Scheme 1) was prepared according to our established methods previously reported. ${ }^{30}$ BTF6 was obtained by procedures similar to those in ref. 41.

Synthesis of BTE-O. BTE-N (100 mg, $0.3 \mathrm{mmol}), \mathrm{KOH}$ (700 $\mathrm{mg}, 12.5 \mathrm{mmol}$ ), and $5 \mathrm{~mL}$ of isopropanol were added to

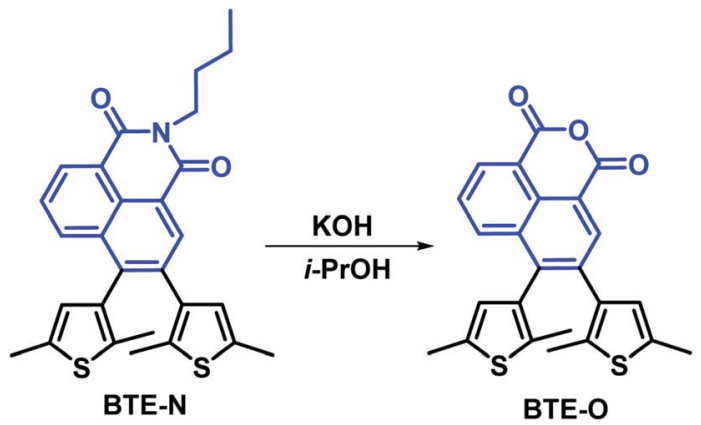

Scheme 1 Synthetic rout of BTE-O

a $50 \mathrm{~mL}$ bottle. The resulting mixture was refluxed under a nitrogen atmosphere in the dark for $48 \mathrm{~h}$ and cooled to room temperature. Then, the mixture was poured into $100 \mathrm{~mL} \mathrm{10 \%} \mathrm{(v/}$ v) $\mathrm{HCl}$ solution, yellow solid was obtained and washed with water three times $(20 \mathrm{~mL} \times 3)$. The solid was dissolved in a small amount of alcohol. After concentration, the compound was purified by column chromatography on silica (petroleum: ethyl acetate, $5: 1, \mathrm{v} / \mathrm{v})$ to yield a yellow solid (57\%). ${ }^{1} \mathrm{H}$ NMR (400 $\left.\mathrm{MHz}, \mathrm{CDCl}_{3}, \mathrm{ppm}\right): \delta=8.62(\mathrm{~d}, J=7.3 \mathrm{~Hz}, 1 \mathrm{H}$, naphthalene-H), 8.59 (s, $1 \mathrm{H}$, naphthalene-H), 8.17 (d, $J=8.5 \mathrm{~Hz}$, $1 \mathrm{H}$, naphthalene-H), $7.74(\mathrm{t}, J=7.4 \mathrm{~Hz}, 1 \mathrm{H}$, naphthalene- $\mathrm{H})$, $6.43(\mathrm{~s}, 1 \mathrm{H}$, thienyl-H), $6.20(\mathrm{~s}, 1 \mathrm{H}$, thienyl-H), $2.44(\mathrm{~s}, 1 \mathrm{H}$, $\left.-\mathrm{CH}_{3}\right), 2.34\left(\mathrm{~s}, 1 \mathrm{H},-\mathrm{CH}_{3}\right), 2.20\left(\mathrm{~s}, 1 \mathrm{H},-\mathrm{CH}_{3}\right), 1.90\left(\mathrm{~s}, 1 \mathrm{H},-\mathrm{CH}_{3}\right)$. ${ }^{13} \mathrm{C}$ NMR (100 $\left.\mathrm{MHz} \mathrm{CDCl}_{3}, \mathrm{ppm}\right): \delta 160.87,160.59,142.06$, 136.71, 136.45, 135.97, 135.69, 135.51, 134.71, 133.91, 132.87, 132.68, 132.01, 129.57, 127.64, 127.43, 126.84, 118.78, 117.42, 15.20, 15.06, 13.85. Mass spectrometry (the ESI positive ion mode for $[\mathrm{M}+\mathrm{H}]^{+}$): calculated $\mathrm{C}_{24} \mathrm{H}_{19} \mathrm{O}_{3} \mathrm{~S}_{2}, 419.0776$, found: 419.0779.

\section{Computational details}

Density functional theory (DFT) calculations were employed to optimize the ground state geometries of BTE-O and the ringclosed isomer of BTE-O (c-BTE-O), using the B3LYP functional ${ }^{42}$ and the $6-31 \mathrm{G}(\mathrm{d})$ basis set. ${ }^{43}$ The polarizable continuum model ${ }^{44}$ was used to model the solvent effects of cyclohexane. At the optimized geometries, the excitation energies and oscillator strengths were calculated by time-dependent DFT (TDDFT) calculations using the CAM-B3LYP functional ${ }^{45}$ and the 6$311+\mathrm{G}(\mathrm{d}, \mathrm{p})$ basis set, ${ }^{\mathbf{4}}$ and the absorption spectra were obtained by Gaussian broadening of the stick spectra with a fullwidth at half-maximum of $0.175 \mathrm{eV}$. All calculations were carried out using the Gaussian09 program package. ${ }^{47}$

\section{Results and discussion}

\section{Molecule design and synthesis}

As shown in Scheme 1, BTE-O was conventionally obtained by alkali treatment of BTE-N with potassium hydroxide. The chemical structure of BTE-O was well confirmed by ${ }^{1} \mathrm{H}$ NMR, ${ }^{13} \mathrm{C}$ NMR and HRMS (see the electronic ESI $\dagger$ for details). 


\section{Photochromism of BTE-O in solvents}

BTE-O was found to dissolve easily in both cyclohexane and acetonitrile to give similar colorless solutions characterised by an intense absorption band in the range of $230-250 \mathrm{~nm}$ and a moderately intense band at 270-350 $\mathrm{nm}$. Irradiating the solutions with $365 \mathrm{~nm}$ light induced obvious changes in the colour of the solutions from colorless to light green in cyclohexane and deep green in acetonitrile, respectively (Fig. 1), thereby resulting in broad absorption bands centered at 412 and $645 \mathrm{~nm}$ (cyclohexane), as well as 414 and $665 \mathrm{~nm}$ (acetonitrile) in the visible range. The colour changes of the solutions were due to the formation of C-BTE-O, a ring-closed isomer of BTE-O with an extended conjugation system, as shown in Scheme 2.

In fact, due to the large chemical environment changes between the ring-open and -closed forms, distinct ${ }^{1} \mathrm{H}$ NMR spectroscopic changes were also observed for BTE-O before and after $365 \mathrm{~nm}$ photo-irradiation in $\mathrm{C}_{6} \mathrm{D}_{6}$, which further confirm the typical photocyclization process. The proton signals of the methylene moieties on thiophene rings located at $\delta=1.72,1.96$ $\left(\mathrm{H}_{\mathrm{h}}, \mathrm{H}_{\mathrm{i}}\right)$, and $\delta=2.06,2.08 \mathrm{ppm}\left(\mathrm{H}_{\mathrm{j}}, \mathrm{H}_{\mathrm{k}}\right)$ for BTE-O in $\mathrm{C}_{6} \mathrm{D}_{6}$, respectively (Fig. $\mathrm{S} 1 \dagger$ ). The different chemical shifts of the two groups of methyl protons are on account of the asymmetric organic framework of the central ethene bridge 1,8-naphthalic anhydride. When irradiated at $365 \mathrm{~nm}$, BTE-O was converted to
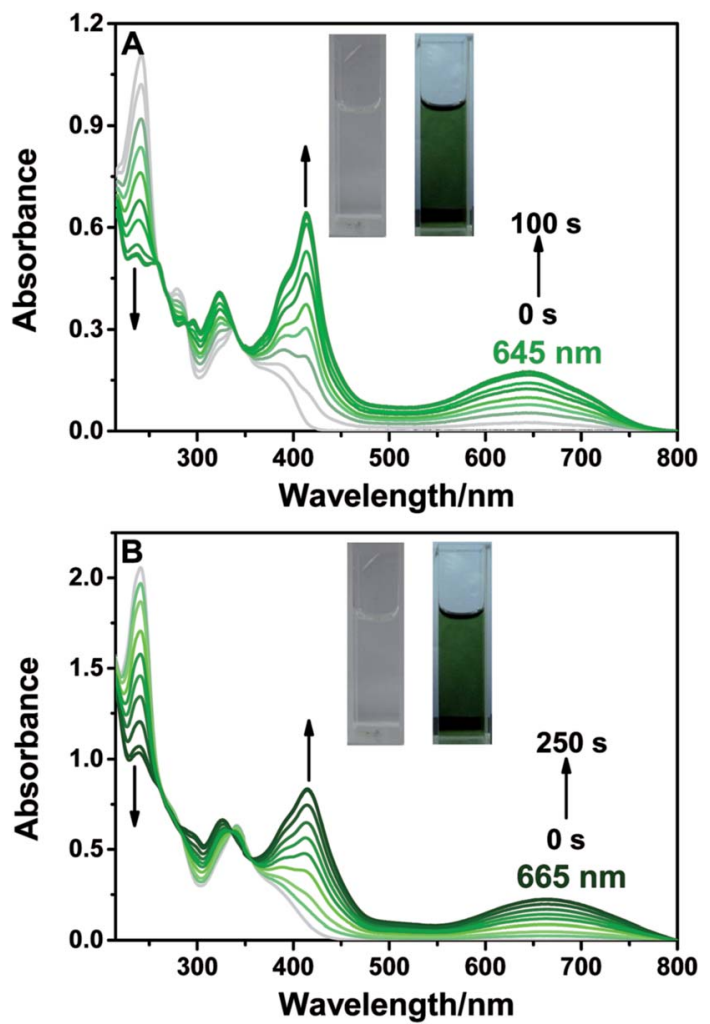

Fig. 1 Absorption spectra changes of BTE-O upon irradiation at $365 \mathrm{~nm}$ in different solutions $\left(5.0 \times 10^{-5} \mathrm{M}\right)(\mathrm{A})$ cyclohexane and (B) acetonitrile. Insets: photographic images of BTE-O in (A) cyclohexane and (B) acetonitrile before (left) and after (right) photochromism (5.0 $\times$ $\left.10^{-4} \mathrm{M}\right)$.

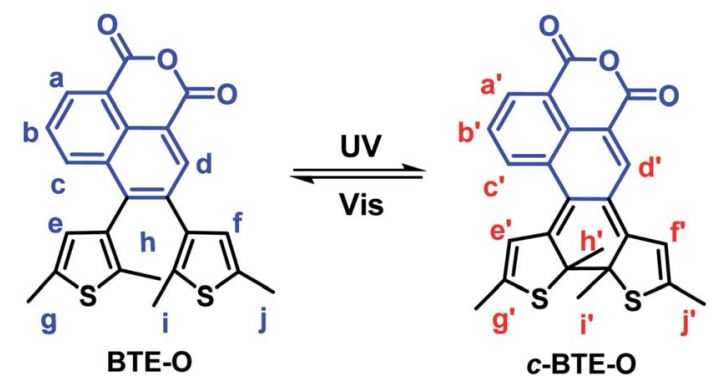

Scheme 2 Chemical structure and photochromism of BTE-O.

c-BTE-O, and new signals of $\mathrm{H}^{\prime}{ }_{\mathrm{h}}, \mathrm{H}_{\mathrm{i}}^{\prime}, \mathrm{H}_{\mathrm{j}}^{\prime}$, and $\mathrm{H}_{\mathrm{k}}^{\prime}$ located at $\delta=$ $1.59,1.70,2.16$, and $2.24 \mathrm{ppm}$ after photocyclization with respect to that of the open form were observed. More obvious signal changes were found for the hydrogens attached to on the thiophene rings and the ethene bridge due to $\pi$ delocalization of 1,8-naphthalic anhydride. It is generally accepted that the proton resonances on the six-membered heterocycles ethene bridges shift upfield after photocyclization reaction of diarylethene due to the aromaticity loss of heterocycles. ${ }^{48,49}$ As expected, the two hydrogen protons located on thiophene $\left(\mathrm{H}_{\mathrm{e}}, \mathrm{H}_{\mathrm{f}}\right)$ in BTE-O shifted from $\delta=6.29$ and $6.18 \mathrm{ppm}$ to $\delta=5.88$ and $5.36 \mathrm{ppm}$, respectively. In addition, the NMR signals of $\mathrm{H}_{\mathrm{a}}, \mathrm{H}_{\mathrm{b}}$, $\mathrm{H}_{\mathrm{c}}$ and $\mathrm{H}_{\mathrm{d}}$ on 1,8-naphthalic anhydride also shifts upfield after photocyclization.

Moreover, a high-performance liquid chromatography (HPLC) analysis was also used to monitor the photocyclization reaction. The conversion ratio from BTE-O to C-BTE-O in the photostationary state $(365 \mathrm{~nm})$ in cyclohexane was $75 \%$, obtained from the corresponding integrated areas of HPLC peaks detected at the isobestic wavelength of $348 \mathrm{~nm}$. The cyclization quantum yield was estimated to be $21.5 \%$ according to that of BTF6.

\section{Fluorescence switching and solvatochromism}

BTE-O exhibited intense fluorescence in both polar and nonpolar solution due to the existence of the fluorophore unit 1,8-naphthalic anhydride (Fig. 2). Moreover, the fluorescence can be reversibly switched on and off via the photochromic reactions between the ring-open and closed isomers of BTE-O. Upon irradiation at $365 \mathrm{~nm}$, fluorescence of BTE-O is quenched in both nonpolar cyclohexane and polar acetonitrile, as reflected by the fluorescence intensity drop by more than $95 \%$ at the photostationary state. The disappearance of fluorescence could be ascribed to the possible quenching channel of Förster resonance energy transfer (FRET) between the ring-open and closed isomers due to the spectra overlap between the absorption and fluorescence spectra. ${ }^{48}$ Upon further irradiation with visible light $(>500 \mathrm{~nm})$, which transfer c-BTE-O to the original open isomer, the fluorescence could be recovered. The fluorescence quantum yield of BTE-O was found to be 0.011 in cyclohexane. A decrease in fluorescence quantum yield was observed as the solvent polarity increases. The fluorescence quantum yields of BTE-O were measured to be 0.009, 0.007, and 0.004 in tetrahydrofuran, dichloromethane, and acetonitrile, respectively. 

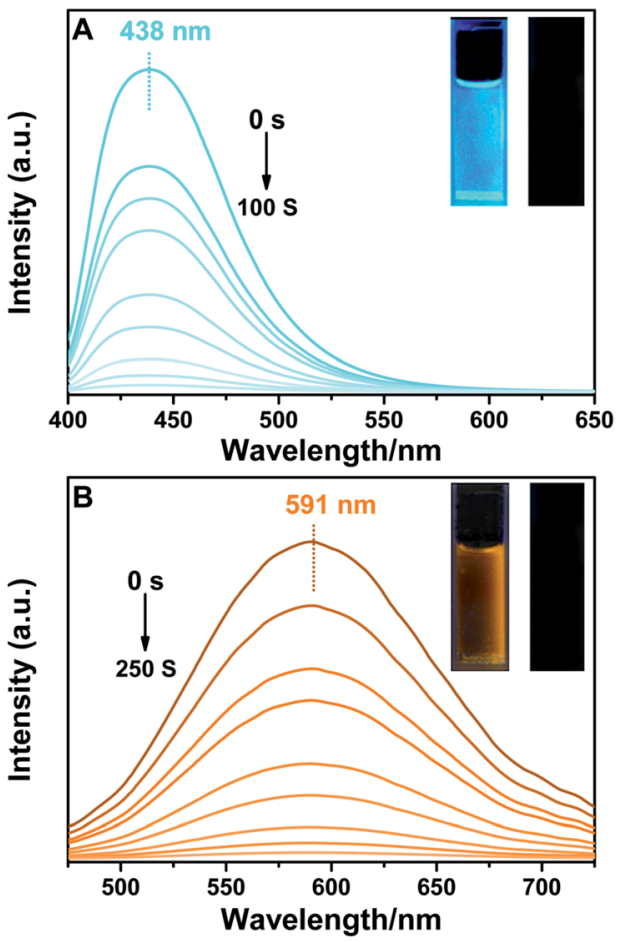

Fig. 2 Fluorescence spectra changes of BTE-O upon irradiation at $365 \mathrm{~nm}$ in (A) cyclohexane and (B) acetonitrile. Inset: fluorescent photographic images in (A) cyclohexane and (B) acetonitrile before (left) and after (right) photoirradiation (excitation wavelength: $380 \mathrm{~nm}$, $\left.5.0 \times 10^{-5} \mathrm{M}\right)$.

More interestingly, a remarkable change of emission characteristics both in terms of the position of spectroscopic emission peak as well as fluorescence lifetime induced by polarity of the solvents, which is commonly reckoned as a special type of solvatochromism, was observed for BTE-O. ${ }^{31}$ As shown in Fig. 3A, the fluorescence maximum of BTE-O gradually red shifted from $438 \mathrm{~nm}$ in nonpolar cyclohexane to $511 \mathrm{~nm}$ in chloroform, $520 \mathrm{~nm}$ in tetrahydrofuran, $533 \mathrm{~nm}$ in dichloromethane, $577 \mathrm{~nm}$ in acetone, and $591 \mathrm{~nm}$ in polar acetonitrile. The solvent polarity trigged a significant bathochromic shift $(153 \mathrm{~nm})$ of the luminescent wavelength of BTE-O with increasing solvent polarity from cyclohexane to acetonitrile.

Meanwhile, the fluorescence lifetime was measure to be 0.35 ns $(34.56 \%)$ and $5.27 \mathrm{~ns}(65.44 \%)$ fitted with double exponential decaying with $\chi^{2}$ of 1.199 in cyclohexane, while in acetone, the value was prolonged to $0.98 \mathrm{~ns}(77.07 \%)$ and $6.34 \mathrm{~ns}(22.93 \%)$ with $\chi^{2}$ of 1.308 . Based on our previous investigation, the distinct solvatochromic shifts as well as the increase on the fluorescence lifetime of BTE-O in different solvents could be attributed to the ICT effect. ${ }^{50,51}$ In general, the ICT excited state is stabilized by the presence of polar solvent molecules, leading to lowered excitation energy and hence remarkable red-shift of the maximal emission peak. The difference in dipole moments between the excited and the ground states was estimated by the Lippert-Mataga equation, which shows the solvent dependence of the Stokes' shift for a compound. The difference in the maximum absorption and emission wavelengths, is fitted to the following equations:
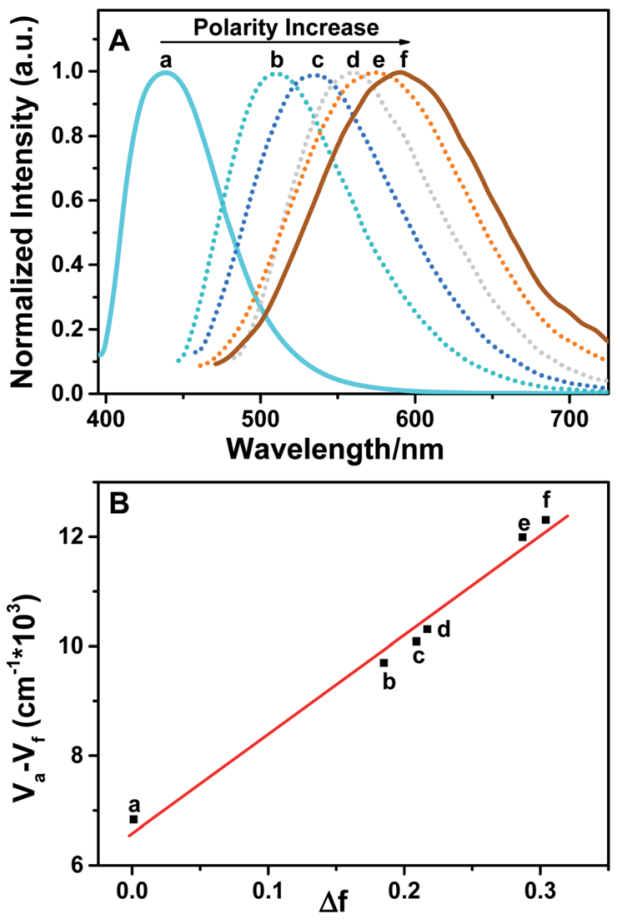

Fig. 3 Normalized fluorescence spectra (A) and Lippert-Mataga plot (B) of BTE-O in solvents with different polarity (excitation wavelength: $380 \mathrm{~nm}, 5.0 \times 10^{-5} \mathrm{M}$ ): (a) cyclohexane $\lambda_{\max }=438 \mathrm{~nm}$ ), (b) chloroform $\lambda_{\max }=511 \mathrm{~nm}$ ), (c) tetrahydrofuran $\lambda_{\max }=520 \mathrm{~nm}$ ), (d) dichloromethane $\lambda_{\max }=533 \mathrm{~nm}$ ), (e) acetone $\lambda_{\max }=577 \mathrm{~nm}$ ), and (f) acetonitrile $\lambda_{\max }=591 \mathrm{~nm}$ ).

$$
\begin{gathered}
\bar{\nu}_{\mathrm{A}}-\bar{\nu}_{\mathrm{F}}=\Delta \bar{\nu}=\frac{2 \Delta f}{h c a^{3}}\left(\mu_{\mathrm{e}}-\mu_{\mathrm{g}}\right)^{2}+\mathrm{const} \\
\Delta f=\frac{\varepsilon-1}{2 \varepsilon+1}-\frac{n^{2}-1}{2 n^{2}+1}
\end{gathered}
$$

where, $\bar{\nu}_{\mathrm{A}}$ and $\bar{\nu}_{\mathrm{F}}$ are the wavenumbers $\left(\mathrm{cm}^{-1}\right)$ of the absorbance and fluorescence emission, $h$ is Plank's constant, $c$ is the velocity of light, $\varepsilon$ and $n$ are the solvent dielectric constant and refraction index. $\Delta f$ is known as orientation polarizability. $\mu_{\mathrm{e}}$ and $\mu_{\mathrm{g}}$ are the dipole moments of the excited and the ground states. ${ }^{52,53}$ As illustrated in Fig. 3B, the Lippert-Mataga plot of the Stokes shift $(\Delta \bar{\nu})$ as a function of orientation polarizability $(\Delta f)$ shows a good linear relationship, which strongly suggests that the spectral behaviour of BTE-O emission is indeed related to ICT characteristic. ${ }^{54}$

\section{Density functional theory (DFT) calculations}

To further understand the impressive solvatochromism of BTEo, density functional theory (DFT) calculations and timedependent DFT (TDDFT) were performed using the Gaussian09 program package. The simulated absorption spectra of BTE-O and c-BTE-O in cyclohexane are shown in Fig. S2. $\dagger$ Compared with experimental measurement, the excitation energies are slightly overestimated by TDDFT calculations using the CAM-B3LYP functional. As shown in Fig. S3, $\dagger$ the HOMO and LUMO of BTE-O are located on the thiophene 


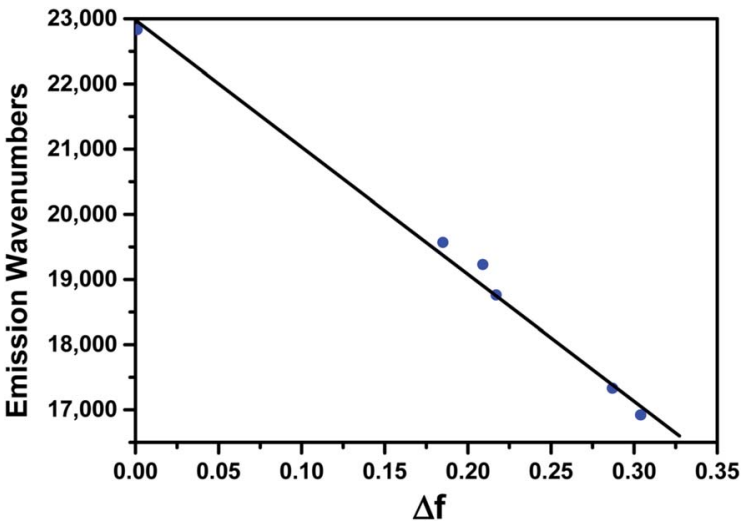

Fig. 4 Fitted linear relationship between emission wavenumber (in $\mathrm{cm}^{-1}$ ) and $\Delta f$

and the 1,8-naphthalic anhydride units, respectively, forming an efficient charge-transfer excitation. Based on the TDDFT results, the absorption bands in $300-400 \mathrm{~nm}$ region for BTE-O are attributed to electronic excitations from the occupied orbitals (mainly HOMO-2 and HOMO) to LUMO (Fig. S3 and Table S1 $\dagger$ ). For BTE-O, HOMO-2 $\rightarrow$ LUMO is a mixture between local excitation and charge-transfer excitation, whereas HOMO $\rightarrow$ LUMO is pure charge-transfer excitation. After photoisomerization, the new absorption band at around $645 \mathrm{~nm}$ is attributed to HOMO $\rightarrow$ LUMO of c-BTE-O, which is a local excitation (Fig. S4 and Table S1†). The new bands at around $400 \mathrm{~nm}$ are contributed by HOMO $\rightarrow$ LUMO +1 and HOMO-1 $\rightarrow$ LUMO excitations of c-BTE-O. Although the absorption spectra of BTE-O show only minor solvent polarity dependence, the experimentally measured emission of BTE-O shows significant red-shift as the polarity of solvent increases (Fig. 3a). The linear relationship between the emission wavenumber and the relationship between the emission wavenumber and the solvent polarity is plotted in Fig. 4. According to methods reported by Pasman et al., the excited state dipole moment of BTE-O is estimated as 26.8 Debye, assuming a solvent radius shell of 5.84 $\AA$ as determined by DFT calculations. ${ }^{55}$ This is in fair agreement with the excited state dipole moment calculated by TDDFT in cyclohexane (20.5 Debye) and in acetonitrile (24.0 Debye). When the excited state has a large dipole, the excited molecule is notably stabilized by polar solvent. Consequently, the excitation energy decreases and the fluorescence maximum wavelength increases.

\section{Conclusions}

In summary, a novel "push-pull" diarylethene molecule BTE-O containing an 1,8-naphthalic anhydride ethene bridge and two substituted 2,5-dimethylthiophene groups is reported. BTE-O exhibits intense fluorescence owing to the existence of aromatic naphthalic ring and the fluorescence can be switched on and off reversibly upon photo-isomerization between the ring-open and -closed isomers of BTE-O. In addition, as demonstrated by experimental data and theoretical calculations, the fluorescence is highly solvent dependent due to intermolecular charge transfer between the electron donating side chains and the electron withdrawing ethene bridge. This provides solvatochromic fluorescence emission with very large shift exceeding $150 \mathrm{~nm}$, which is of interest for potential applications such as monitoring microenvironmental polarity in chemical and biological systems.

\section{Acknowledgements}

This work was supported by NSFC/China (21503136), Ministry of education of China (PCSIRT_IRT_16R49), Shanghai Sci. \& Tech. and Edu. Committee (14YF1409200) and Shanghai Gaofeng \& Gaoyuan Project for University Academic Program Development. We also thank the Swedish National Infrastructure for Computing (SNIC) for providing computational resources for project SNIC 2015-16/10.

\section{Notes and references}

1 M. Irie, T. Fukaminato, K. Matsuda and S. Kobatake, Chem. Rev., 2014, 114, 12174-12277.

2 J. Zhang, Q. Zou and H. Tian, Adv. Mater., 2013, 25, 378-399.

3 C. Jia, A. Migliore, N. Xin, S. Huang, J. Wang, Q. Yang, S. Wang, H. Chen, D. Wang, B. Feng, Z. Liu, G. Zhang, D.-H. Qu, H. Tian, M. A. Ratner, H. Q. Xu, A. Nitzan and X. Guo, Science, 2016, 352, 1443-1445.

4 T. Tsuruoka, R. Hayakawa, K. Kobashi, K. Higashiguchi, K. Matsuda and Y. Wakayama, Nano Lett., 2016, 16, 74747480 .

5 S. Z. Pu, Q. Sun, C. B. Fan, R. J. Wang and G. Liu, J. Mater. Chem. C, 2016, 4, 3075-3093.

6 S. Fredrich, R. Göstl, M. Herder, L. Grubert and S. Hecht, Angew. Chem., Int. Ed., 2016, 55, 1208-1212.

7 H. Tian and Y. L. Feng, J. Mater. Chem., 2008, 18, 1617-1622.

8 C. Yun, J. You, J. Kim, J. Huh and E. Kim, J. Photochem. Photobiol., C, 2009, 10, 111-129.

9 J. Andreasson and U. Pischel, Chem. Soc. Rev., 2015, 44, 1053-1069.

10 F. M. Raymo and M. Tomasulo, J. Phys. Chem. A, 2005, 109, 7343-7352.

11 G. Li, L. Ma, G. Liu, C. Fan and S. Pu, RSC Adv., 2017, 7, 20591-20596.

12 S. Chen, W. Li, X. Li and W.-H. Zhu, RSC Adv., 2015, 5, 87626-87634.

13 C. G. P. Taylor, J. R. Piper and M. D. Ward, Chem. Commun., 2016, 52, 6225-6228.

14 T. Fukaminato, T. Sasaki, T. Kawai, N. Tamai and M. Irie, J. Am. Chem. Soc., 2004, 126, 14843-14849.

15 S.-J. Lim, B.-K. An, S. D. Jung, M.-A. Chung and S. Y. Park, Angew. Chem., Int. Ed., 2004, 43, 6346-6350.

16 M. Bossi, V. Belov, S. Polyakova and S. W. Hell, Angew. Chem., Int. Ed., 2006, 45, 7462-7465.

17 M. Balter, S. Li, M. Morimoto, S. Tang, J. Hernando, G. Guirado, M. Irie, F. M. Raymo and J. Andreasson, Chem. Sci., 2016, 7, 5867-5871.

18 F. Hu, C. Jiang, W. Liu, J. Wang, J. Yin and S. H. Liu, Dyes Pigm., 2017, 136, 161-167. 
19 Y. Cai, Z. Guo, J. Chen, W. Li, L. Zhong, Y. Gao, L. Jiang, L. Chi, H. Tian and W.-H. Zhu, J. Am. Chem. Soc., 2016, 138, 2219-2224.

20 X. X. Zhang, R. J. Wang, C. B. Fan, G. Liu and S. Z. Pu, Dyes Pigm., 2017, 139, 208-217.

21 H. Dong, M. Luo, S. Wang and X. Ma, Dyes Pigm., 2017, 139, 118-128.

22 M. Berberich, A.-M. Krause, M. Orlandi, F. Scandola and F. Würthner, Angew. Chem., Int. Ed., 2008, 47, 6616-6619.

23 W. Li, C. Jiao, X. Li, Y. Xie, K. Nakatani, H. Tian and W. Zhu, Angew. Chem., Int. Ed., 2014, 53, 4603-4607.

24 S. Chen, L.-J. Chen, H.-B. Yang, H. Tian and W. Zhu, J. Am. Chem. Soc., 2012, 134, 13596-13599.

25 H.-H. Liu and Y. Chen, J. Mater. Chem., 2011, 21, 1246-1249. 26 J. Guérin, A. Léaustic, J. Berthet, R. Métivier, R. Guillot, S. Delbaere, K. Nakatani and P. Yu, Chem.-Asian J., 2017, 12, 853-859.

27 S.-C. Pang, H. Hyun, S. Lee, D. Jang, M. J. Lee, S. H. Kang and K.-H. Ahn, Chem. Commun., 2012, 48, 3745-3747.

28 Q. Ai, S. Pang and K.-H. Ahn, Chem.-Eur. J., 2016, 22, 656662.

29 K. Suzuki, T. Ubukata and Y. Yokoyama, Chem. Commun., 2012, 48, 765-767.

30 X. Meng, W. Zhu, Q. Zhang, Y. Feng, W. Tan and H. Tian, J. Phys. Chem. B, 2008, 112, 15636-15645.

31 W. Zhu, X. Meng, Y. Yang, Q. Zhang, Y. Xie and H. Tian, Chem.-Eur. J., 2010, 16, 899-906.

32 W. Zhu, L. Song, Y. Yang and H. Tian, Chem.-Eur. J., 2012, 18, 13388-13394.

33 Z. Yang, J. Cao, Y. He, J. H. Yang, T. Kim, X. Peng and J. S. Kim, Chem. Soc. Rev., 2014, 43, 4563-4601.

34 C. Reichardt, Chem. Rev., 1994, 94, 2319-2358.

35 X. Y. Shen, Y. J. Wang, E. Zhao, W. Z. Yuan, Y. Liu, P. Lu, A. Qin, Y. Ma, J. Z. Sun and B. Z. Tang, J. Phys. Chem. C, 2013, 117, 7334-7347.

36 R. Hu, C. F. A. Gómez-Durán, J. W. Y. Lam, J. L. BelmonteVázquez, C. Deng, S. Chen, R. Ye, E. Pena-Cabrera, Y. Zhong, K. S. Wong and B. Z. Tang, Chem. Commun., 2012, 48, 10099-10101.

37 K. Cao, M. Farahi, M. Dakanali, W. M. Chang, C. J. Sigurdson, E. A. Theodorakis and J. Yang, J. Am. Chem. Soc., 2012, 134, 17338-17341.

38 X. Qian, Z. Zhu and K. Chen, Dyes Pigm., 1989, 11, 13-20.

39 I. Grabtchev and T. Philipova, Dyes Pigm., 1995, 27, 321-325.

40 S. Fukumoto, T. Nakashima and T. Kawai, Angew. Chem., Int. Ed., 2011, 50, 1565-1568.
41 K. Uchida, E. Tsuchida, Y. Aoi, S. Nakamura and M. Irie, Chem. Lett., 1999, 28, 63-64.

42 A. D. Becke, J. Chem. Phys., 1993, 98, 5648-5652.

43 W. J. Hehre, R. Ditchfield and J. A. Pople, J. Chem. Phys., 1972, 56, 2257-2261.

44 J. Tomasi, B. Mennucci and R. Cammi, Chem. Rev., 2005, 105, 2999-3094.

45 T. Yanai, D. P. Tew and N. C. Handy, Chem. Phys. Lett., 2004, 393, 51-57.

46 R. Krishnan, J. S. Binkley, R. Seeger and J. A. Pople, J. Chem. Phys., 1980, 72, 650-654.

47 M. J. Frisch, G. W. Trucks, H. B. Schlegel, G. E. Scuseria, M. A. Robb, J. R. Cheeseman, G. Scalmani, V. Barone, B. Mennucci, G. A. Petersson, H. Nakatsuji, M. Caricato, X. Li, H. P. Hratchian, A. F. Izmaylov, J. Bloino, G. Zheng, J. L. Sonnenberg, M. Hada, M. Ehara, K. Toyota, R. Fukuda, J. Hasegawa, M. Ishida, T. Nakajima, Y. Honda, O. Kitao, H. Nakai, T. Vreven, J. Montgomery, A. Jr, J. E. Peralta, F. Ogliaro, M. Bearpark, J. J. Heyd, E. Brothers, K. N. Kudin, V. N. Staroverov, R. Kobayashi, J. Normand, K. Raghavachari, A. Rendell, J. C. Burant, S. S. Iyengar, J. Tomasi, M. Cossi, N. Rega, J. M. Millam, M. Klene, J. E. Knox, J. B. Cross, V. Bakken, C. A. damo, J. Jaramillo, R. Gomperts, R. E. Stratmann, O. Yazyev, A. J. Austin, R. Cammi, C. Pomelli, J. W. Ochterski, R. L. Martin, K. Morokuma, V. G. Zakrzewski, G. A. Voth, P. Salvador, J. J. Dannenberg, S. Dapprich, A. D. Daniels, Ö. Farkas, J. B. Foresman, J. V. Ortiz, J. Cioslowski and D. J. Fox, Gaussian 09, Revision D.01, Gaussian Inc., Wallingford, CT, 2009.

48 Y. Yang, Y. Xie, Q. Zhang, K. Nakatani, H. Tian and W. Zhu, Chem.-Eur. J., 2012, 18, 11685-11694.

49 S. H. Kawai, S. L. Gilat, R. Ponsinet and J.-M. Lehn, Chem.Eur. J., 1995, 1, 285-293.

50 Z. R. Grabowski, K. Rotkiewicz and W. Rettig, Chem. Rev., 2003, 103, 3899-4032.

51 B. Valeur, Molecular fluorescence: principles and applications, Wiley-VCH Verlag GmbH, New York, 2001.

52 A. Arjona-Esteban, M. Stolte and F. Würthner, Angew. Chem., Int. Ed., 2016, 55, 2470-2473.

53 M. Chen, H. Nie, B. Song, L. Li, J. Z. Sun, A. Qin and B. Z. Tang, J. Mater. Chem. C, 2016, 4, 2901-2908.

54 A. Marini, A. Muñoz-Losa, A. Biancardi and B. Mennucci, J. Phys. Chem. B, 2010, 114, 17128-17135.

55 P. Pasman, F. Rob and J. W. Verhoeven, J. Am. Chem. Soc., 1982, 104, 5127-5133. 